\title{
Treatment of focal epithelial hyperplasia with trichloroacetic acid
}

\author{
Harris Ricardo J1', Carmona Lorduy $\mathrm{M}^{2}$, Díaz Caballero $\mathrm{A}^{3}$
}

\begin{abstract}
Focal epithelial hyperplasia is a benign disease which has a chronic course that manifests as characteristic multiple small papules or nodules. They are predominantly found in the oral mucosa, gingiva and tongue. The surface of the lesions is smooth and it varies in size. It is an asymptomatic disease caused by human papillomavirus, affecting mainly children and adolescents. In this report, we describe four cases referred to the Stomatology and Oral Surgery Department of the Faculty of Dentistry, Cartagena University with a diagnosis of focal epithelial hyperplasia. Clinical features and histopathological characteristics of the patients were recorded. We also describe the properties and advantages of trichloroacetic acid as a therapeutic method.
\end{abstract}

Rev. Clin. Periodoncia Implantol. Rehabil. Oral Vol. 5(3); 140-143, 2012.

Key words: Focal epithelial hyperplasia, Papilloma virus infections, trichloroacetic acid (Mesh Database).

\section{INTRODUCTION}

The human papillomavirus (HPV) has a wide spectrum of diseases that affects cutaneous and mucosal areas of the body, from benign warts to invasive carcinoma, among the benign pathologies that affect the oral mucosa have been reported squamous papilloma, verruca vulgaris, condyloma acuminatum and focal epithelial hyperplasia ${ }^{(1)}$.

Focal epithelial hyperplasia (FEH) is a disease that mainly affects the pediatric population, although some cases have been reported in adults and several members of one family, the highest incidence occurs in certain ethnic groups as American Indians, Greenland Eskimos and South American community dwellers, is caused by human papillomavirus, the most common associated subtypes are 13 and $32^{(2,3)}$.

The focal epithelial hyperplasia it is characterized by multiple lesions appear as circumscribed, sessile, rounded papules, with a color similar to the adjacent mucosa or a whitish color, the surface of the lesions is smooth although sometimes it can be rough with low growth rate. The most common sites of involvement are the gingiva, buccal mucosa and the tongue. Lesions involving the oral mucosa are resilient and asymptomatic ${ }^{(4)}$.

Histological findings consist of parakeratin layering, extensive acanthosis, epithelial cells of the spinous layer with enlarged nucleus, degeneration Koilocytosic and mitosoid cells, Molecular techniques such as polymerase chain reaction (PCR) or in-situ hybridization can be used to examine the presence of human papilloma virus (HPV) in many instances $^{(1,5)}$. Differential diagnosis consists of condyloma acuminatum, verruca volgaris, papilloma, irritation fibroma, and Cowden syndrome since they have some clinical similarities like lesion type, color and location ${ }^{(6)}$.

Focal epithelial hyperplasia is considered as a regressive lesion although some cases have been reported when lesions remain up to 50 years, resulting in psychosocial problems such as rejection ${ }^{(7)}$. Treatment modalities include surgical excision, cryosurgery, sulfonamides, vitamin A, CO2 laser, immunomodulation, (Imiquimond), and interferon alfa ${ }^{(8)}$.

\section{TRICHLOROACETIC ACID}

Trichloroacetic acid (TCA) was created in the 1830 and used in humans for the first time in 1926 , is composed of carbon, chlorine, oxygen and hydrogen; it produces a denaturalization, precipitation and destruction of the lesions due to chemical coagulation of the affected tissue $^{(9,10)}$. Authors such as Buck and Taner et al, have reported that the TCA can be used to treat genital warts in pathologies such as papilloma, condyloma and verruca vulgaris, being effective with a high rate of success and low morbidity. The main complication described with higher frequency is the presence of ulcerative lesions ${ }^{(11,12)}$. In relation with the toxicity, has been reported in rats the lethal dosis is about $400 \mathrm{mg} / \mathrm{Kg}^{(13)}$.

Regarding the use in the oral cavity; Little et al described that one of the alternatives for a successful treatment in oral infections by human papillomavirus is the application of trichloroacetic acid and they recommended concentrations between 80 and $90 \%{ }^{(14)}$. Harris et al reported a case of a patient with focal epithelial hyperplasia, where the application of trichloroacetic acid in a solution concentration of 90 percent resulted in a complete resolution of the lesions after two topical applications $^{(15)}$. Perez et al affirmed that a good treatment in patients diagnosed with focal epithelial hyperplasia is the topical application of TCA in a concentration to $80 \%$, each application should be performed fortnightly or monthly completing four to five sessions ${ }^{(16)}$. Mata et al reported a case series of patients with focal epithelial hyperplasia which were treated with cryotherapy and TCA observing a complete resolution of the lesions in all of the cases within two years of follow-up ${ }^{(17)}$.

\section{MATERIALS AND METHODS}

In this report, we describe four cases referred to Stomatology and Oral Surgery Department of Cartagena University Dental School with a clinical and histopathological diagnosis of focal epithelial hyperplasia treated with TCA in a concentration to $80 \%$ considering the presence of multiple lesions, age, gender, and high anxiety of the patient in order to avoid traumatic procedures. The legal representatives of patients agreed with the therapeutic and signed the informed consent, approved by ethics committee of Cartagena University.

For the acid application, firstly it must wash with water and dry the surface of the lesion, secondly applying the ATA to the lesion using a swab and wait 60 seconds until it turns white in color, then apply in the oral cavity a mixture of water and bicarbonate in order to neutralize the $\mathrm{pH}$ of the acid and remove debris that may affected the surrounding tissue, after that it is necessary to repeat the process in each of the lesions ${ }^{(18)}$.

1. Odontólogo. Universidad del Sinú Cartagena. Especialista en Estomatología y Cirugía Oral, Universidad de Cartagena. Candidato a Magíster en Microbiología Molecular, Universidad Libre. Docente Corporación Universitaria Rafael Núñez. Colombia.

2. Odontóloga. Universidad de Cartagena. Especialista en Estomatología, Universidad de Buenos Aires. Magíster en Educación Universidad del Norte. Docente Titular, Universidad de Cartagena. Colombia.

3. Odontólogo. Universidad De Cartagena. Especialista en Periodoncia, Universidad Javeriana. Magíster en Educación Universidad del Norte. Estudiante Doctorado en Ciencias Biomédicas, Universidad de Cartagena. Docente titular Universidad de Cartagena. Director Grupo de investigaciones GITOUC. Colombia.

Correspondence author: Jonathan Harris Ricardo. j.harris.r@hotmail. Facultad de Odontología, Universidad de Cartagena. Barrio Zaragocilla Campus de la Salud. Cartagena. D. T. y C. Colombia. Trabajo recibido el 01/03/2012. Aprobado para su publicación el 03/07/2012. 
CASE 1

A 7-year-old Colombian female referred to the University of Cartagena Dentist School. She complained of painless lesions on the buccal mucosa which had been presented for 8 months, she had no skin lesions or history of immunosuppressive and metabolic disease. She was otherwise healthy and had no history of allergy or any inherited disease. None of her family members had similar oral lesions.

Clinical examination revealed multiple slightly protruded, soft, asymptomatic papules on the buccal mucosa, lower labial mucosa and the anterior third of the tongue. The papules were the same color as the surrounding mucosa or whiter, with a smooth surface ranging from 2 to 5 $\mathrm{mm}$ in diameter (Figure 1).

A clinical diagnosis of FEH was proposed based on the clinical features. Excisional biopsy was performed of lower labial mucosa lesion to confirm the diagnosis and histological study reported epithelial hyperplasia without atypia.

Trichloroacetic acid was applied to $80 \%$ following the above application mode (Figure 2) describing the absence of symtomps. First control was performed fifteen days after the application observing multiple lesions in lower labial mucosa, buccal mucosa and tongue, but with a decrease in diameter and height, then five applications were performed every fortnight noticing in control number 6 a completed resolution of lesions and all the characteristics of a healthy mucosa, such as good elasticity, pale pink mucosa, vascularized, moist and shiny (Figure 3). It's no sign of recurrence after one year follow up.

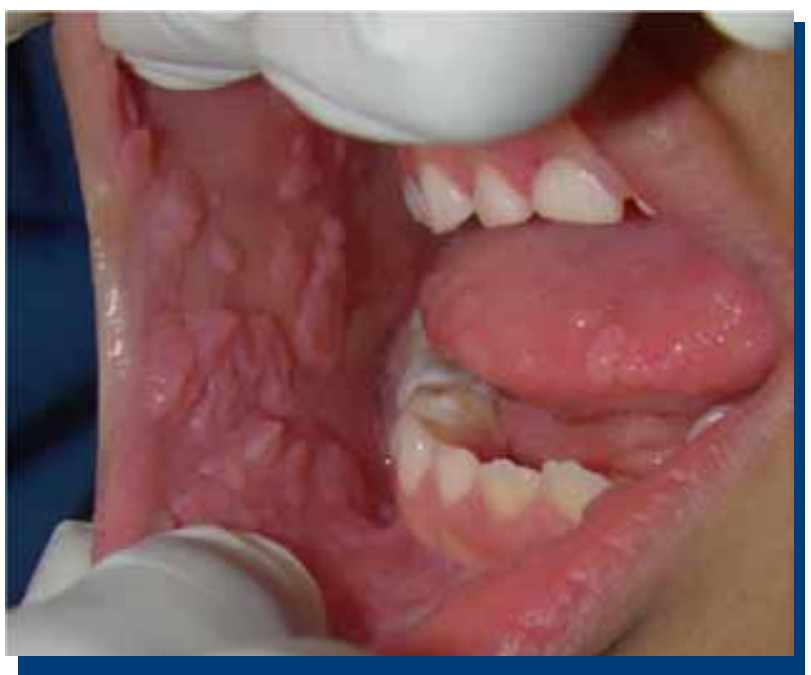

Figure 1. Multiple papules, located in the buccal mucosa, labial and the anterior third of the tongue.

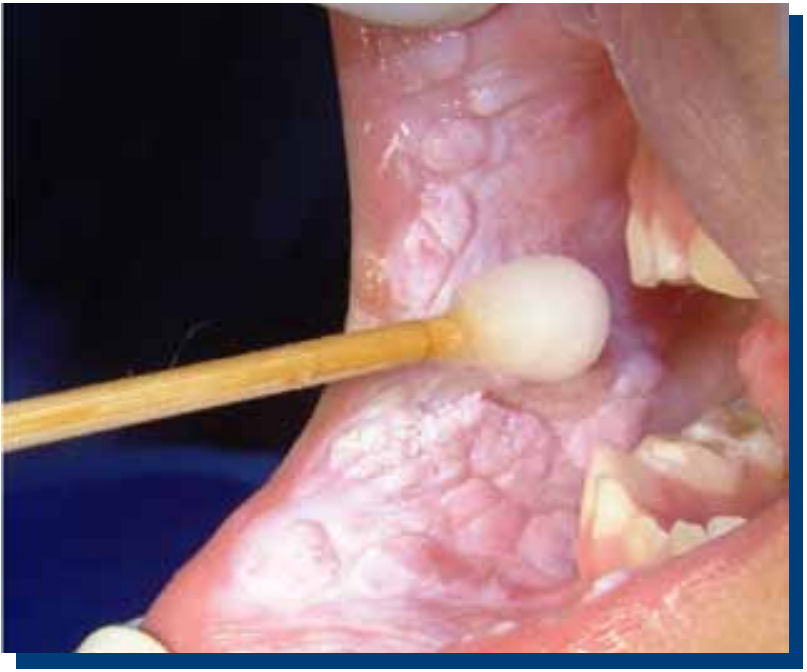

Figure 2. Trichloroacetic acid application over the lesions at $80 \%$.

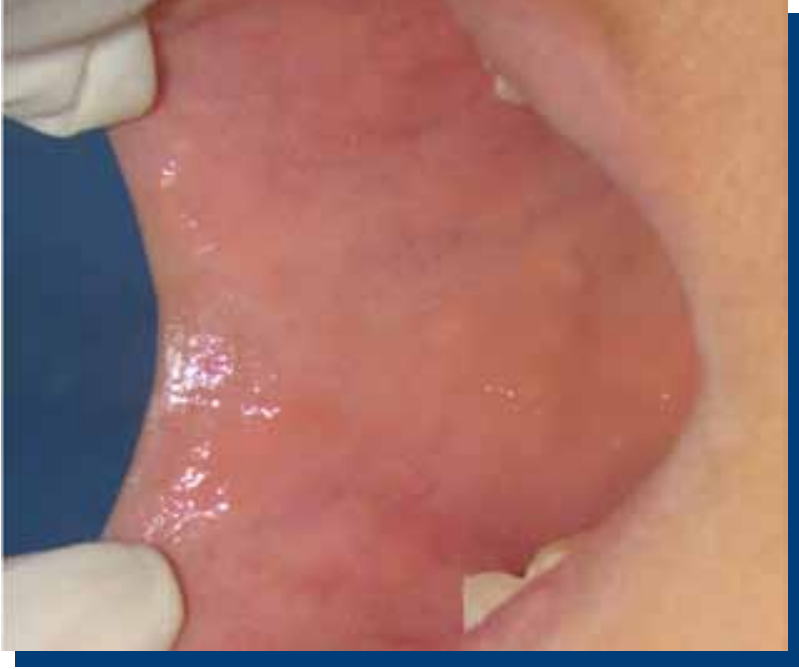

Figure 3. Clinical control observing full resolution of the lesions and all the feature of a healthy mucosa.

\section{CASE 2}

A 10-year-old Colombian female referred to the University of Cartagena Dentist Faculty with the chief complain of multiple papules on the buccal mucosa, which had been presented for one year and increase in number over time. The medical history and family history were unremarkable. Clinical examination revealed multiple papules rounded, pale, protruded, soft, asymptomatic of $2-4 \mathrm{~mm}$ in diameter with sessile base on the anterior labial gingiva, located in upper and lower labial mucosa, anterior third of buccal mucosa and lateral border of tongue left side.

Excisional biopsy was performed in one of the lesions, the histological study showed acanthosis, papillomatosis, hyperkeratosis, elongation and anastomosis of the interpapillary ridges, presence of large vacuolated cells with round nucleus intensely basophils that indicates koilocytosis compatible with epithelial hyperplasia without atypia (Figure 4).

Trichloroacetic acid was applied to $80 \%$ without symptoms reported, after four weeks the first control was made, observing resolution of the lesions in almost every area except in left buccal mucosa, a second application was applied on the persistent lesion and was controlled within two weeks observing absence of the lesions and a healthy mucosa. There is no sign of recurrence after 18 months follow up.

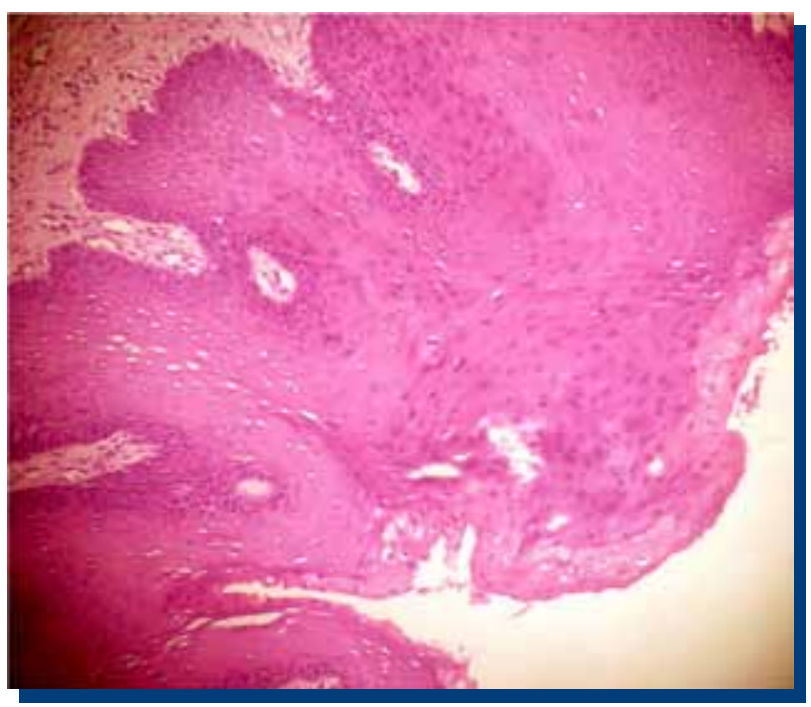

Figure 4. Prominent acanthosis of the epithelium with elongated rete ridges, presence of acantosis and mitosoidal cells. 


\section{CASE 3}

A 14-year-old female with no relevant personal or family history consulted for asymptomatic lesions on the buccal mucosa that had spread slowly and progressively. The physical examination revealed numerous, well-defined papules variable in size, painless, pinkish-white color, with a rough surface located on the upper and lower lips and buccal mucosa.

Excisional biopsy was performed in one of the upper labial mucosa lesions and histological study reported epithelial hyperplasia without atypia.

It was applied TCA on the lesions, he did not refer any pain, the first control was performed three weeks later observing complete resolution of all the lesions and oral mucosa in good condition. There is no recurrence 15 months after being applied the treatment.

\section{CASE 4}

A 12-year-old male patient, which had multiple lesions in the oral mucosa of 6 months duration, the evaluation by the Service denied any high-risk sexual contact or family history of these lesions.

Clinical examination revealed a number of pale protruded, soft, asymptomatic papules, variables on size, located on the buccal mucosa, tongue and upper and lower lips (Figure 5).

Excisional biopsy was performed in one of the lesions, the histological study showed epithelial hyperplasia without atypia.

Trichloroacetic acid was applied to $80 \%$ without referred any pain, after 15 days first control was made, observing multiple lesions but with a decrease in diameter and height, then, two applications were made every fifteen days observing absence of the lesions and a healthy mucosa (Figure 6), after 6 month there is no sign of recurrence.

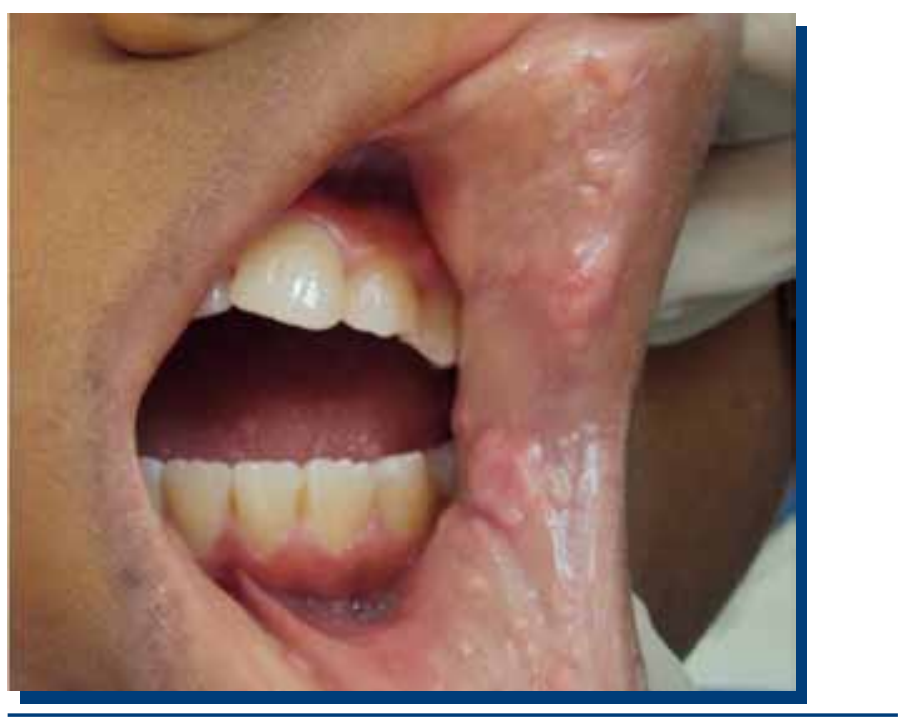

Figure 5. Multiple papules on lip, buccal and tongue mucosa.

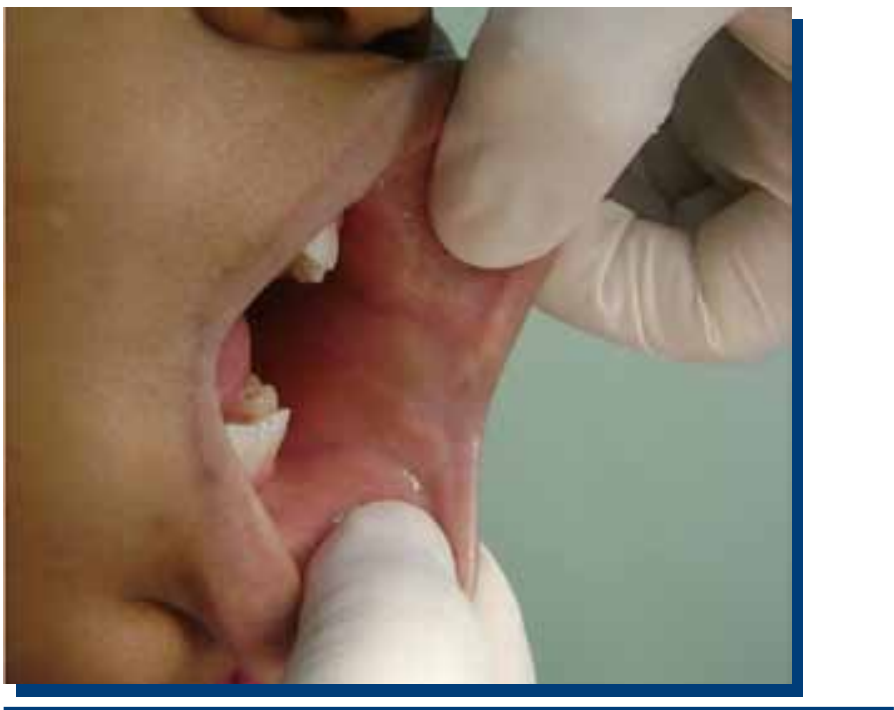

Figure 6. Resolution of lesions after the application with trichloroacetic acid.

\section{DISCUSSION}

The FEH is a benign proliferative disease of chronic course, affecting the oral mucosa. Ledesma et al, described that focal epithelial hyperplasia is characterized by multiple papules with a color similar to adjacent mucosa, the most frequent site of involvement are the buccal mucosa, lower and upper lip mucosa, lip commisure and tongue. The lesions appear as circumscribed, soft, non-tender, flattened or rounded papules, the surface of the lesions is smooth and it varies from 0.1 to 0.5 $\mathrm{cm}$ in diameter ${ }^{(19)}$, agreeing with the present series of cases where the clinical manifestations were similar.

Referring to age and gender Saunders et al and Ledesma et al, reported that FEH mainly affects the pediatric population and the condition is more common among women ${ }^{(19,20)}$, coinciding with the current report of four cases, which mostly affected women with three cases and the age range was between 7 and 14 .

Concentration of TCA for use in the oral mucosa is important in the FEH. Little et al recommend that in order to get good results we should have concentrations between 80 and $90 \%{ }^{(14)}$, Perez et al reported the use of TCA to $80 \%$ obtaining resolution of lesions ${ }^{(16)}$, this coincides with our four cases where the application of TCA to $80 \%$ resulted in complete disappearance of lesions, the first case after the sixth application, the second case after the second application, the third just with one application and finally number four with three applications.

With regard to the mode of application of TCA, Perez et al established that after the application of TCA on the lesion, a white frosting develops, then use water bicarbonate to remove the acid and make the applications every two weeks ${ }^{(16)}$, agreeing with the present report because after applying the TCA a white frosting was obtained caused by chemical coagulation that produces the acid, after 60 seconds was applied a mixture of water and bicarbonate in the oral cavity to neutralize the acid $\mathrm{pH}$ and eliminate residues that may affect the adjacent tissues.

In relation to resolution's time of lesions after the application with TCA, Mata et al reported a series of four cases of patients with FEH treated with cryotherapy and TCA, noting complete resolution of lesions in each case at 18 months, 8 months, two years and one year respectively ${ }^{(17)}$, differing on the duration of this four cases since the complete absence of lesions occurred in the first case 3 months after beginning the treatment, the second 45 days after, the third 21 days after the first application of TCA and the fourth case at 45 days.

\section{CONCLUSION}

According to the series of cases reported, the implementation of the ATA as a therapeutic method in the HEF was an efficient and effective technique, achieving resolution of the lesions quickly, less traumatically, without creating anxiety and fear to the patient.

\section{CONFLICT OF INTEREST STATEMENT}

None declared. 


\section{REFERENCES}

1. Kumaraswamy $\mathrm{KL}$, Vidhya M. Human papilloma virus and oral infections: An update. J Cancer Res Ther, 2011 Apr-Jun; 7(2): 120-127.

2. López-Jornet $P$, Camacho-Alonso F, Berdugo L. Oral focal epithelial hyperplasia N Y State Dent J, 2010 Jun-Jul; 76(4): 54-55.

3. Feller L, Khammissa RA, Wood NH, Malema V, Meyerov R, Lemmer J. Focal epithelial hyperplasia (Heck disease) related to highly active antiretroviral therapy in an HIV-seropositive child. A report of a case, and a review of the literature. SADJ, 2010 May; 65(4): 172-175.

4. Hall C, McCullough M, Angel C, Manton D. Multifocal epithelial hyperplasia: A case report of a family of Somalian descent living in Australia. Oral Surg Oral Med Oral Pathol Oral Radiol Endod, 2010 Jan; 109(1): 20-24.

5. Mosannen-Mozaffari P, Falaki F, Amirchaghmaghi M, Pakfetrat A, Dalirsani Z, Saghafi-Khadem S. Multifocal epithelial hyperplasia, a rare oral infection in Asia: Report of twelve cases in Iran. Med Oral Patol Oral Cir Bucal, 2010 Jul 1; 15(4): 591-595.

6. Hashemipour MA, Shoryabi A, Adhami S, Mehrabizadeh Honarmand H. Extensive focal epithelial hyperplasia. Arch Iran Med, 2010 Jan; 13(1): 48-52.

7. González-Losa MR, Suarez-Allén RE, Canul-Canche J, Conde-Ferráez L, EljureLopez N. Multifocal epithelial hyperplasia in a community in the Mayan area of Mexico. Int J Dermatol, 2011 Mar; 50(3): 304-309.

8. Villanueva S, Hernández A, Castaño A, Miñano R, Córdoba S, Borbujo J. Multifocal epithelial hyperplasia: A familial case. An Pediatr (Barc), 2010; 73(6): 357-360.

9. Yasar S, Mansur AT, Serdar ZA, Goktay F, Aslan C. Treatment of focal epithelia hyperplasia with topical imiquimod: Report of three cases. Pediatr Dermatol, 2009 Jul-Aug; 26(4): 465-468.

10. Kopera D, Holubar K. Trichloroacetic acid in dermatology of 1911. Int J Dermatol, 1998 Mar; 37(3): 205.
11. Buck H Jr. Warts (genital). Clin Evid (Online). 2010 Aug 13; 1602.

12. Taner ZM, Taskiran C, Onan AM, Gursoy R, Himmetoglu O. Therapeutic value of trichloroacetic acid in the treatment of isolated genital warts on the external female genitalia. J Reprod Med, 2007 Jun; 52(6): 521-525.

13. Ficha de Datos de Seguridad Según Reglamento (CE) 1907. Citado 2006 articulo 31. www.carloerbareagenti.com/Repository/DIR199/CH0809 E.pdf.

14. Little J, Falace D, Miller C, Rhodus N. Dental management of the medically compromised patientet. $5^{\text {th }}$ ed. Mosby. 1998. p. 319, 320.

15. Harris J, Rebolledo M, Camacho F, Carmona M, Díaz A. Ácido tricloroacético, una opción terapéutica en la hiperplasia epitelial focal. Presentación de un caso. Av Odontoestomatol, 2010; 26(6): 323-328.

16. Pérez A, del Pino G, López M. Hiperplasia epitelial focal: Actualidades y tratamiento. Rev Mex Cir Bucal Max, 2010 Sep; 6(3): 111-115.

17. Mata M, Fermín Y, Oliver M, Rondón A. Focal epithelial hyperplasia: Report of four cases. Dermatol Venez, 1996; 34(1): 29-32.

18. Beutner KR, Wiley DJ, Douglas JM, Tyring SK, Fife K, Trofatter K. Genital warts and their treatment. Clin Infect Dis, 1999 Jan; 28(1): 37-56.

19. Ledesma C, Vega E, Garcés M, Cardiel M, Juárez C. Multifocal epithelia hyperplasia. Report of nine cases. Med Oral Patol Oral Cir Bucal, 2005 Nov-Dic 10(5): 394-401.

20. Saunders NR, Scolnik D, Rebbapragada A, Koelink E, Craw L, Roth S, Aronson L, Perusini S, Silverman MS. Focal epithelial hyperplasia caused by human papillomavirus 13. Pediatr Infect Dis J, 2010 Jun; 29(6): 550-552. 